\title{
Characterisation of prostate cancer lesions in heterozygous Men1 mutant mice
}

\author{
Christelle Seigne ${ }^{1}$, Sandra Fontanière ${ }^{1,2}$, Christine Carreira ${ }^{1,2}$, Jieli Lu ${ }^{1,7}$, Wei-Ming Tong ${ }^{2,3}$, Bernard Fontanière ${ }^{4}$, \\ Zhao-Qi Wang ${ }^{2,5}$, Chang Xian Zhang ${ }^{1,7^{*}}$, Lucien Frappart ${ }^{6}$
}

\begin{abstract}
Background: Mutations of the MEN1 gene predispose to multiple endocrine neoplasia type 1 (MEN1) syndrome. Our group and others have shown that Men1 disruption in mice recapitulates MEN1 pathology. Intriguingly, rare lesions in hormone-dependent tissues, such as prostate and mammary glands, were also observed in the Men 1 mutant mice.
\end{abstract}

Methods: To study the occurrence of prostate lesions, we followed a male mouse cohort of $47 \mathrm{Men}^{+/-}$mice and 23 age-matched control littermates, starting at 18 months of age, and analysed the prostate glands from the cohort.

Results: Six Men $1^{+/-}$mice (12.8\%) developed prostate cancer, including two adenocarcinomas and four in situ carcinomas, while none of the control mice developed cancerous lesions. The expression of menin encoded by the Men 1 gene was found to be drastically reduced in all carcinomas, and partial LOH of the wild-type Men 1 allele was detected in three of the five analysed lesions. Using immunostaining for the androgen receptor and p63, a basal epithelial cell marker, we demonstrated that the menin-negative prostate cancer cells did not display p63 expression and that the androgen receptor was expressed but more heterogeneous in these lesions. Furthermore, our data showed that the expression of the cyclin-dependent kinase inhibitor CDKN1B (p27), a Men1 target gene known to be inactivated during prostate cell tumorigenesis, was notably decreased in the prostate cancers that developed in the mutant mice.

Conclusion: Our work suggests the possible involvement of Men1 inactivation in the tumorigenesis of the prostate gland.

\section{Background}

Mutations of the MEN1 gene predispose patients to multiple endocrine neoplasia type 1 (MEN1), characterised by the occurrence of multiple endocrine tumours affecting mainly the parathyroid glands, the endocrine pancreas and the anterior pituitary [1]. Shortly after the identification of the MEN1 gene, several nonendocrine tumours were also reported in MEN1 patients, such as lipoma and angioma [2,3]. The MEN1 gene encodes a primarily nuclear-localised protein named menin that has been shown to interact with a variety of other proteins [4]. In particular, its interaction with several transcriptional factors and co-factors suggests that menin

\footnotetext{
* Correspondence: zhang@lyon.fnclcc.fr

'CNRS UMR5201, Laboratoire de Génétique Moléculaire, Signalisation et Cancer, Centre Léon Bérard, Lyon F-69008, France
}

may act as an adaptor protein involved in the regulation of gene expression. However, little is known about the in vivo physiological function of menin and the in vivo importance of the aforementioned protein-protein interactions, especially in the endocrine cells commonly affected in MEN1 disease.

By disrupting Men1 in mice, we and others have previously shown that, while homozygous Men1 mutant mice die embryonically, heterozygous Men1 mutant mice largely recapitulate the major endocrine lesions seen in MEN1 pathology [5-8]. However, these mice develop several types of neoplastic lesions that are rarely seen in MEN1 patients, such as high frequency sex-cord stromal cell tumours in $88 \%$ of aged male mice and $50 \%$ of female mice $[6,8]$. Intriguingly, we have found three cases $(3 / 36,8,3 \%)$ of breast cancer in heterozygous Men1 female mice [6], and Crabtree et al. documented 
one case of prostate cancer developed in their heterozygous Men1 mouse cohort [7]. Consistent with these observations, Dreijerink et al. have shown that menin interacts physically, in a ligand-dependent manner, with several nuclear receptors, such as the oestrogen receptor (ER) [9] and peroxisome proliferator activated receptor gamma (PPAR $\gamma$ ) [10], and that menin acts as a coactivator of nuclear receptor mediated transcription. These studies raise the question of whether Men1 inactivation could predispose to the development of hormonedependent tumours. To investigate the possible link between the development of prostate cancer and Men1 disruption, we followed a cohort of aged male heterozygous Men 1 mutant mice. Several cases of prostate cancer were found in this group, whereas no cases were seen in control animals. Interestingly, the expression of menin was inactivated in these prostate cancers, and partial LOH (loss of heterozygosity) of the wild-type Men1 allele was found. Gene expression analyses further revealed that the expression of CDKN1B (cyclin-dependent kinase inhibitor 1B, also called p27), a known menin target gene $[11,12]$, was markedly reduced in the analysed prostatic carcinomas.

\section{Methods}

\section{Men1 mutant mice}

$M e n 1^{+/-}$mice carrying an inactivated Men1 allele were generated as previously described [5]. These mutant mice with mixed C57BL6/129-Sv genetic background give rise to multiple endocrine lesions mimicking the human MEN1 tumour spectra as previously described [6]. Littermate $M e n 1^{+/-}$and $M e n 1^{+/+}$male mice were used for the analyses to limit the bias possibly originating from the mixed genetic background. All animal experiments were conducted in accordance with accepted standards of animal care and were approved by the International Agency for Research on Cancer's Animal Care and Use Committee.

\section{Genotyping and LOH analysis}

PCR genotyping analyses were performed to determine the presence of the wild-type and mutant Men 1 alleles as previously described [6]. For LOH analysis, meninimmunostained prostate sections were used to locate menin-negative lesions. Genomic DNA was then extracted from corresponding microdissected paraffinembedded sections as previously described [6]. The wild-type (+) and mutant (-) Men1 alleles were first amplified from $1 \mu \mathrm{g}$ of genomic DNA by PCR, carried out as described for genotyping [6], using the following three primers: 2f0, 5-CTTACCTCTTCTCATGTCTG; 2r0, 5-CTCAGTACATTGCACGGAGA; and tk1.1, 5-GCGTTGCGTGGGGTCAG. Southern blots were then performed by standard methods on these PCR products using a probe for each Men1 allele generated by amplification of genomic DNA from a Men1 heterozygous mutant mouse with the PCR described above. Autoradiography films were scanned with the EC3 imaging system (UVP Bioimaging Systems), and the intensity of each band was quantified with Visionworks LS software. The ratio between the intensities of the + and - Men 1 alleles (+/- ratio) was then calculated to evaluate the loss of the wild-type Men1 allele.

\section{Histopathological analyses}

Prostate glands and adjacent tissues were collected from wild-type and heterozygous Men1 mutant mice, fixed in $4 \%$ buffered formalin for at least $24 \mathrm{~h}$ at room temperature, and processed for paraffin-embedding, sectioning $(3 \mu \mathrm{m})$ and haematoxylin and eosin staining. Histopathological examination of prostate samples was performed independently by three pathologists (B Fontanière, L Frappart and WM Tong), including a mouse model specialist (WM Tong), on a blinded basis according to the criteria recommended by the consensus report from the Bar Harbor meeting of the mouse models of human cancer consortium (MMHCC) prostate pathology committee [13]. The WHO Classification of Tumours of the Urinary System and Male Genital Organs (2004) was also used. More than 3 prostate sections were examined for each mouse and lobe origin was distinguished during the scoring process. The final diagnosis was then reached by a common decision.

\section{Immunostaining analysis}

Immunohistochemical (IHC) staining was performed on prostate serial sections as previously described [6], using antibodies against menin (BL342, Bethyl Laboratories, Montgomery, TX, USA, 1:6000), androgen receptor (C-19, Santa Cruz Biotech, Santa Cruz, CA, USA, 1:4000) and CDKN1B (F-8, Santa Cruz Biotech, 1:2000). In all these analyses, a control without primary antibody was systematically included to rule out non-specific staining due to secondary antibody reactivity (data not shown). Immunofluorescence (IF) double staining was performed on paraffin-embedded prostate sections. Briefly, after endogenous peroxidase inactivation, antigen retrieval and antibody diluent treatment (DAKO, Capinteria, CA, USA), sections were incubated overnight with primary antibody against menin (BL342, 1:6000). After secondary antibody incubation (anti-rabbit, Vector Lab, $1: 200)$, the signal was amplified using the ABC Vectastain elite kit (Vector Lab) and the TSA Cyanine 3 kit (PerkinElmer, Waltham, MA, USA, 1/100). Slides were saturated once more in DAKO antibody diluent and then incubated overnight with primary antibodies against p63 (Ab-1, Oncogene Research products, San Diego, CA, USA, 1:2000) or CDKN1B (Santa Cruz 
Biotech, 1:2000), followed by incubation with secondary antibody (anti-mouse, Vector Lab, 1:200). The signals were revealed by the ABC kit and TSA Cyanine 5 (PerkinElmer, 1/100). Slides were mounted in IF Vectashield DAPI-containing mounting medium (Vector Lab), and the immunofluorescence signal was visualised with a confocal microscope (LEICA TCS SP2).

\section{Results}

\section{A proportion of aged heterozygous Men 1 mutant mice develop prostate cancer}

To determine the effect of Men1 inactivation on prostate cancer development in mice, we followed a cohort of 47 male mutant mice $\left(M e n 1^{+/-}\right)$and 23 wild-type $\left(M e n 1^{+/+}\right)$age-matched littermate mice from 18 to 26 months of age, based on a previous study that showed no prostate cancer in younger mice [6].

Histopathologic analysis of the prostate glands from these mice was performed in accordance with the criteria defined by the MMHCC [13]. A comparison between age-matched Men1 wild-type and mutant mice revealed notable histological differences, showing a marked increase in cancer incidence in $M e n 1^{+/-}$prostates (Table 1) and a significantly decreased proportion of mutant mice with normal prostate histology. The results showed $30.4 \%$ of Men 1 wild-type prostates with normal histology while only $6.4 \%$ of prostate glands from mutant mice were free of lesions ( $p=0.0266$, Fisher's two-tailed exact test). Normal prostate tissue presented as a single layer of secretory epithelial cells lined by a well-defined outer basal cell layer, with uniform small nuclei containing inconspicuous or small nucleoli. The epithelial hyperplasia diagnosed in this study appeared as increased numbers of epithelial cells, with or without atypia, associated with increased gland size. The intraluminal proliferation of markedly atypical epithelial cells, with tufted, cribriform or micropapillary growth pattern, was recognised histologically as mouse prostatic intraepithelial neoplasia (mPIN) (Figure 1B). Carcinomas were characterised by frequent mitotic

Table 1 Morphologic alterations in the prostate glands of male heterozygous Men 1 mice

\begin{tabular}{ccc}
\hline Type of pathology & Men $\mathbf{1}^{+/+}$ & Men $^{+/-}$ \\
\hline Normal prostate & $7 / 23(30.4 \%)^{\mathrm{a}}$ & $3 / 47(6.4 \%)^{*}$ \\
Hyperplasia & $10 / 23(43.5 \%)$ & $22 / 47(46.8 \%)$ \\
mPIN & $6 / 23(26.1 \%)$ & $16 / 47(34 \%)$ \\
Carcinoma & $0 / 23(0 \%)$ & $6 / 47(12.8 \%)$ \\
\hline
\end{tabular}

$M e n 1^{+/+}$and $\mathrm{Men}^{+/-}$male mice were monitored for cancer development and examined by histology between 18 and 26 months. ${ }^{a}$ Number of mice of each histological category over the total number of the mice examined. The percentage of mice in each histological category is shown in parentheses. For each mouse, only the most severe type of lesion was taken into account. For this reason, mPINs observed in four mice having carcinoma lesions were not counted in this table. ${ }^{*} p=0.0266$ (Fisher's exact test). figures, apoptotic debris and cytologic atypia, such as amphophilic cytoplasm, increased nuclear-cytoplasmic ratio, hyperchromasia, prominent and multiple nucleoli, chromatin clumping and pleomorphism (Figure 1C, D, E).

Hyperplastic and mPIN lesions, mainly presenting in the lateral and anterior lobes of prostatic glands, were observed with similar frequency in mutant and wildtype aged mice (Table 1, 43.5\% in $M e n 1^{+/+}$versus $46.8 \%$ in $M e n 1^{+/-}$mice for hyperplasia and $26.1 \%$ in $M e n 1^{+/+}$ versus $34 \%$ in $M e n 1^{+/-}$mice for mPIN), and a few of them were also found in dorsal and ventral lobes. However, the incidence of mPIN in mutant mice was underestimated because four mPIN lesions observed in mutant mice with in situ carcinomas were not counted, since only the most severe lesion was taken into account for each mouse. The real incidence of mPIN in $M e n 1^{+/-}$ mice should thus be $42.5 \%$. The occurrence of both hyperplasia and mPIN lesions has already been reported in some wild-type mouse strains [14].

More importantly, our analysis revealed that, of 47 heterozygous Men1 mutant mice, six developed prostate cancers $(12.8 \%)$. No prostate carcinoma was ever found in age-matched $\mathrm{Men} \mathrm{1}^{+/+}$littermates (0/23). Among the prostate cancers observed in $M e n 1^{+/-}$mice, four were identified as in situ prostate carcinomas presenting as microscopic lesions (one in dorsal prostate, shown in Figure $1 \mathrm{C}$, two in lateral prostate, and one in anterior prostate), one papillary adenocarcinoma in the anterior prostate (Figure 1D) and one differentiated invasive adenocarcinoma in the lateral prostate (Figure 1E, F), with the latter two visible on gross examination. Invasive tissue was found in epithelial areas lacking an intact basal cell layer, with cancerous cells invading the surrounding stroma (Figure 1F). Among the observed prostatic lesions, none displayed histopathological features typical of neuroendocrine differentiation (solid or sheet-like proliferation of closely spaced oval or spindle cells with scant cytoplasm and hyperchromatic nuclei, with areas of rosette formation) [13].

Taken together, our data revealed the development of prostate carcinomas in a small proportion of aged heterozygous $M e n 1$ mutant mice.

\section{Menin expression is inactivated in cancerous lesions mainly through LOH}

Menin expression was assessed in the different prostatic lobes from Men 1 wild-type mice using either IHC for menin or double IF with antibodies against menin and p63, a basal epithelial cell marker. IHC analysis revealed that menin expression, which is mainly nuclear but can also be detected in the cytoplasm, was found in all prostatic lobes from Men1 wild-type mice in both luminal and basal prostatic epithelial cells (Figure 2A) but not in interstitial cells. Double IF staining of menin and p63 

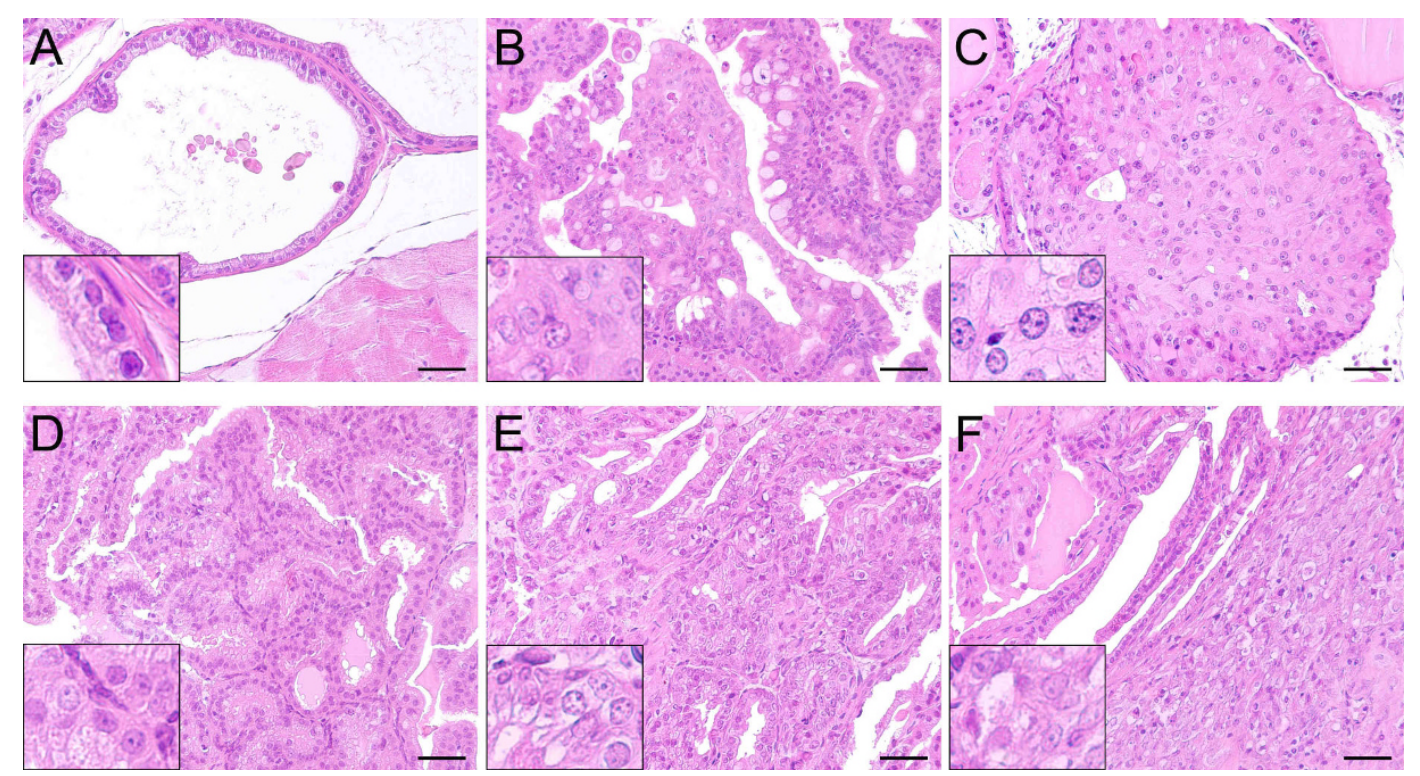

Figure 1 Precancerous and cancerous lesions are detected in aged male heterozygous Men 1 mutant mice. Haematoxylin and eosin staining of a normal lateral prostate lobe from a 24-month-old $M e n 1^{+/+}$mouse (A) and precancerous or cancerous lesions observed in prostate glands from heterozygous Men1 mutant mice (B-F). (B) mPIN found in the anterior prostate with a signet ring variant: cytoplasmic vacuoles displacing the cell nuclei (21-month-old mouse). (C) In situ carcinoma in the dorsal prostate (26-month-old mouse). (D) Adenocarcinoma in the anterior prostate with branching and papillary infolding (23-month-old mouse). (E) Differentiated invasive adenocarcinoma in the lateral prostate (in situ component) from a 23-month-old mouse. (F) Invasive component of the same lesion as in (E) showing invasion to the prostatic connective tissue. Insets show a magnified view of a part of the prostate glands. Scale bars, $50 \mu \mathrm{m}$.

confirmed this result (Figure 3A-D). To evaluate the association between the occurrence of prostatic lesions in heterozygous Men 1 mice and inactivation of the Men1 gene, we examined menin expression by IHC in the corresponding lesions. We found that menin expression was readily detectable by IHC in all four tested mPIN lesions from WT mice (data not shown), but clearly reduced in two of four mPIN lesions from mutant mice (Figure 2B, F). The data suggest that, although a large proportion of mPINs observed in mutant mice occur independently of Men1 inactivation, as those seen in wild-type mice, some may still be related to menin loss. In contrast to mPIN lesions, no menin expression was detectable in the six prostate cancers found in $\mathrm{Men1}^{+/-}$mice (Figure 2C-E and 2G-I), suggesting that prostate cancer in these mice was likely caused by menin inactivation, rather than the secondary effects of MEN1 pathology, such as gene expression and/or hormone disturbance in endocrine tissues. In two of the prostate cancers shown in Figure 2 (panels $\mathrm{D}, \mathrm{H}$ and $\mathrm{E}, \mathrm{I}$ ), a small number of cells remain positive for menin expression. We reasoned that these cells were in fact normal basal epithelial cells that remained in cancer lesions, which was confirmed by further analyses (see below).

To further study the related mechanisms leading to menin inactivation, we tested the presence of $\mathrm{LOH}$ in
mPIN from $M e n 1^{+/-}$mice displaying reduced menin expression and in menin-negative carcinoma lesions detected by IHC analysis. To this end, the tested tissues were scraped from the corresponding paraffin-embedded slides, and genomic DNA was extracted from each lesion. Genotyping analysis demonstrated that partial $\mathrm{LOH}$ was indeed found in three of five analysed precancerous and cancerous lesions (Figure 2J). The quantification of amplified products corresponding to $\mathrm{MenI}^{+}$and $M e n 1^{-}$alleles from the tail of a $M e n 1^{+/-}$mouse was used as a control, and an identical intensity of both alleles was achieved, thus giving a $+/-$ ratio equal to one. The intensity of the wild-type allele $(+)$, but not the mutant allele (-), was reduced in two mPINs (PIN1 and 2, both showing reduction of menin expression by IHC analysis) and in an adenocarcinoma lesion (ADC) from $\mathrm{Men} 1^{+/-}$ mice, as demonstrated by the lower $+/$ - ratios for these lesions when compared with the control (Figure 2J). We assume that the residual wild-type allele, amplified from the tested lesions, was derived mainly from the remaining normal basal cells within the lesions, which were shown to retain menin expression. The result suggests that $\mathrm{LOH}$ of the remaining wild-type Men 1 allele may be one of the mechanisms leading to menin inactivation in the prostate cancers developed in this model, although we cannot exclude that other mechanisms may also be involved. 

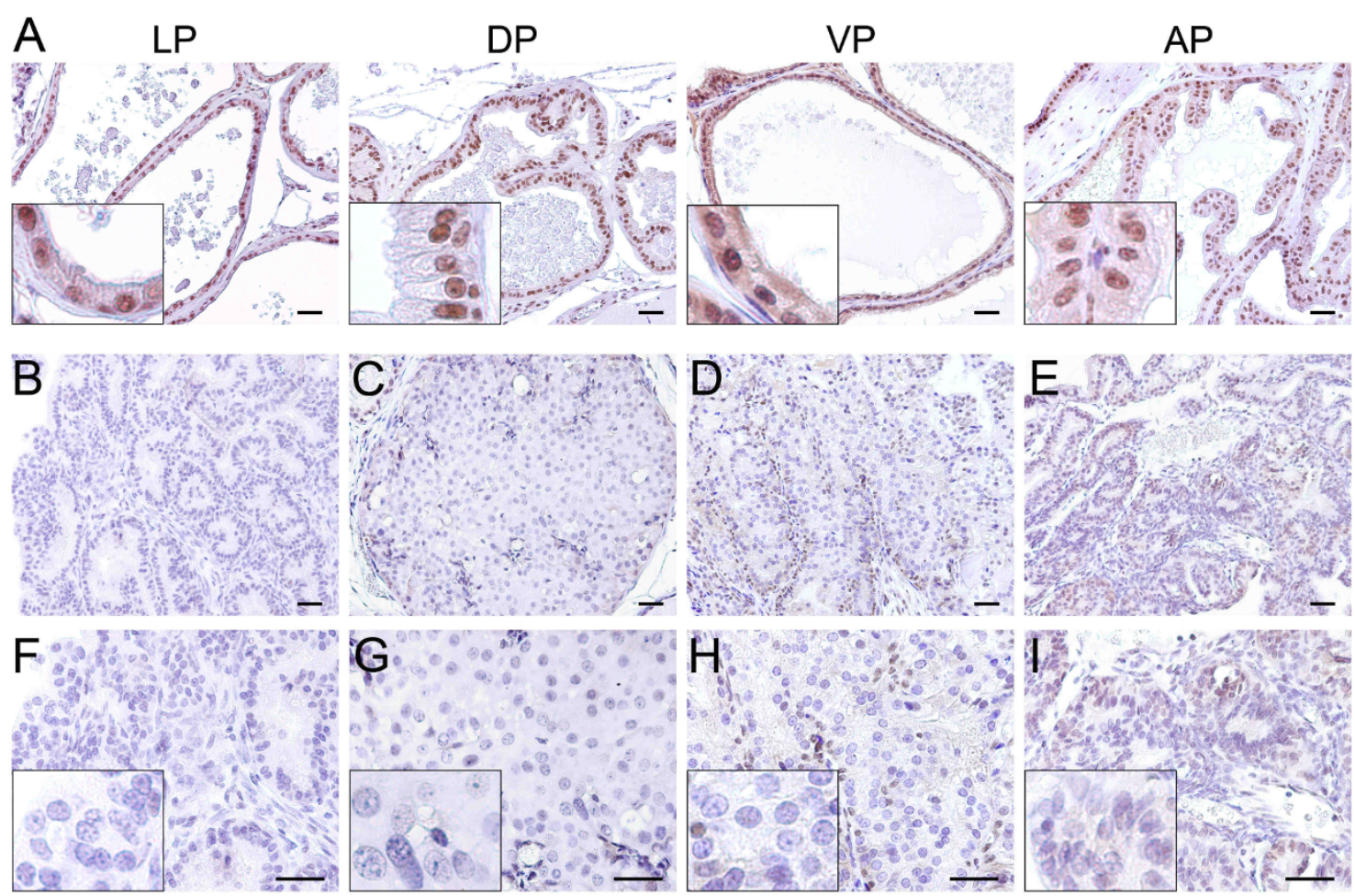

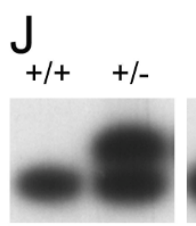

1
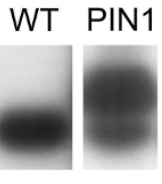

0.6

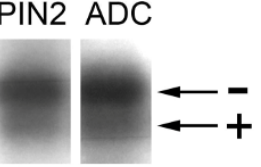

$0.38 \quad 0.5$ Ratio +/-

Figure 2 Menin expression is inactivated in prostate cancers from $\mathbf{M e n} \mathbf{1}^{+/-}$mice. Microscopic images of prostate glands from Men $1^{+/+}(\mathrm{A})$ and $\mathrm{Men}^{+/-}$mice (B-I) subjected to menin detection by IHC. Menin is widely expressed in the nuclei of prostate epithelial cells in the lateral $(\mathrm{LP})$, dorsal (DP), ventral (VP) and anterior (AP) prostate from a 21-month-old $M e n 1^{+/+}$mouse (A), but is completely inactivated in two of four tested mPINs and in all six prostatic cancerous lesions in $\mathrm{Men}^{1^{+-}}$mice. Four representative types of lesions are shown: mPIN from a 21-monthold $\mathrm{Men}^{1^{+-}}$mouse $(\mathrm{B}, \mathrm{F})$, an in situ prostate carcinoma from a 26-month-old mouse $(\mathrm{C}, \mathrm{G})$, a well-differentiated adenocarcinoma from a 23month-old mouse $(D, H)$ and a papillary adenocarcinoma from a 23-month-old mouse $(E, I)$. Panels F-I are two-fold magnifications of the upper panels (B-E). Insets show an amplified view of a part of the prostate glands. Scale bars, $50 \mu \mathrm{m}$. (J) Representative results from two independent $\mathrm{LOH}$ analyses of prostatic lesions in Men $1^{+-}$mice. Semi-quantitative amplification of Men 1 wild-type (+) and mutant (-) alleles with PCR was performed on DNA samples extracted from microdissected paraffin-embedded sections from Men $1^{+/+}$normal prostate (WT) and prostate lesions from $\mathrm{Men}^{+/-}$mice, including two mPIN (PIN1 and PIN2) and one adenocarcinoma (ADC). Tail DNA from wild-type (+/+) and heterozygous (+/-) Men1 mice were used as controls. The intensity of both alleles ( + and -) was quantified and used to calculate the +/- ratio, which was compared with the $+/$ - ratio obtained from the controls.

\section{The prostate cancers developed in heterozygous Men 1 mutant mice do not express p63 and display heterogeneous AR expression}

Although a loss of menin expression and a partial $\mathrm{LOH}$ were found in some mPINs from Men 1 mutant mice, these occurred at similar frequencies in wild-type and mutant mice. The present study therefore focused on the analysis of the prostate cancers arising in Men 1 mutant mice. To further characterise the observed cancer lesions, expression of the basal epithelial marker p63 was analysed using double IF staining, since the diagnosis of cancerous lesions can often be based on the disruption of the basal cell layer indicated by the absence or greatly reduced number of p63-positive basal cells [15]. Menin-negative cancerous cells were negatively stained with basal cell marker p63 (Figure 3E-H). In addition, normal p63-positive basal cells, which retained menin expression, were greatly reduced in number and scattered in the cancerous lesions, showing a disruption of the basal cell layer (Figure $3 \mathrm{H}$, white arrowhead). The data were thus consistent with our histopathologic findings and indicated that menin 


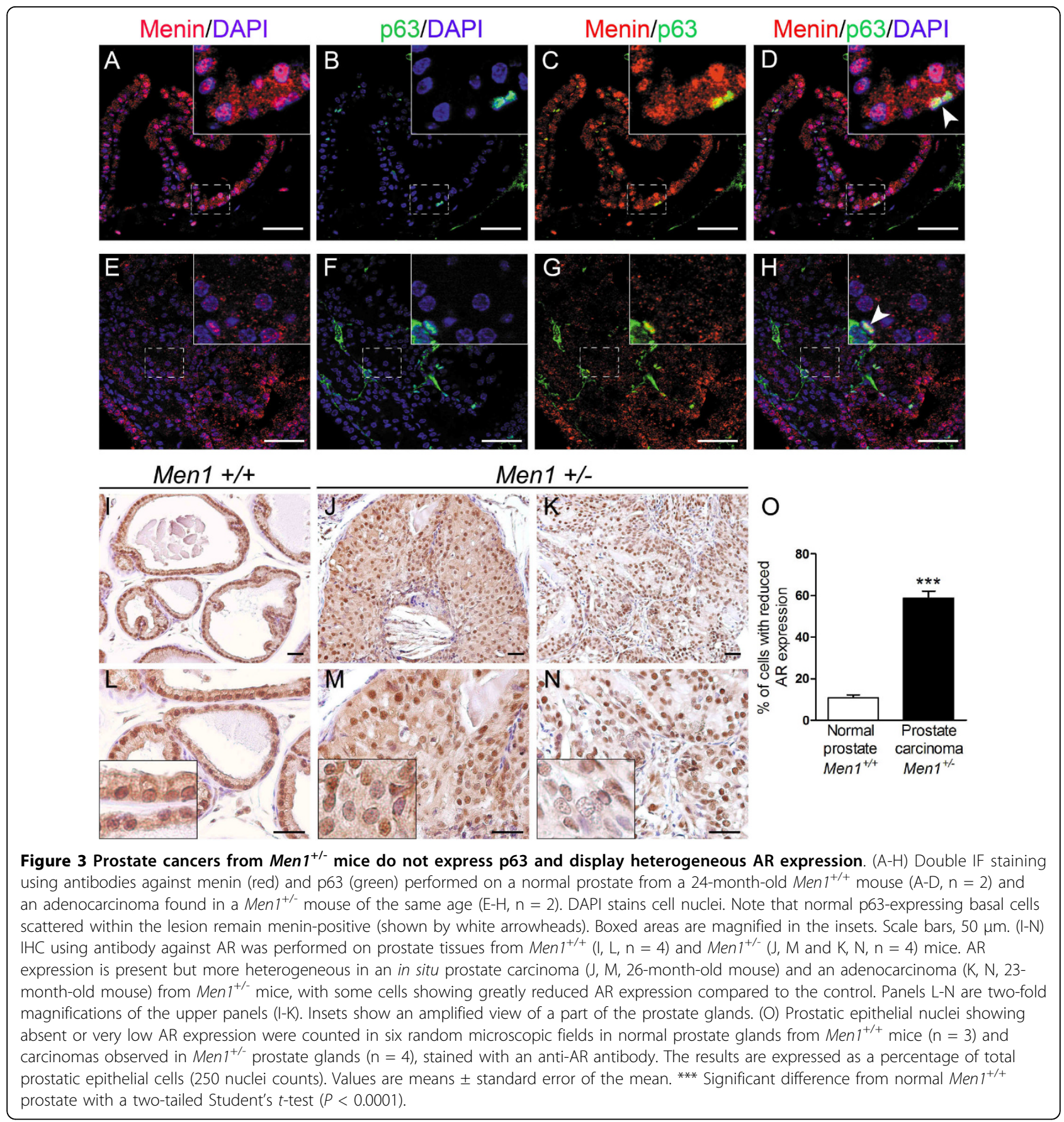

inactivation did not occur in basal cells, confirming what we had speculated on the basis of the results obtained by menin IHC.

Prostatic cells express the androgen receptor (AR) and respond to the androgen pathway that regulates prostate growth, apoptosis and differentiation. Nearly $70 \%$ of clinical prostate cancer cases are AR positive. It is generally considered that AR expression in prostate cancer cells reflects not only the differentiation status of the cells, but also their sensitivity to anti-AR treatment. We therefore evaluated AR expression using IHC in different prostate tissue samples. Normal prostate tissue from $\mathrm{Men}^{+/+}$mice showed strong AR nuclear staining in both luminal and basal epithelial cells, as well as in many stromal cells (Figure 3I, L), as previously described in the literature [16-18]. AR was clearly expressed in an in situ carcinoma (Figure 3J, M) and an adenocarcinoma (Figure $3 \mathrm{~K}, \mathrm{~N}$ ) and showed a heterogeneous expression 
pattern in these lesions in comparison with the normal control prostate (Figure 3I, L), with some cells showing absent or very low AR staining. Quantitation of epithelial cell nuclei displaying either no AR expression or very low staining revealed a significant increase in the number of cells with altered AR expression in prostate carcinomas from Men1 mutant mice compared with normal $\mathrm{Men}^{+/+}$prostate glands (Figure 3O).

The data demonstrated the disruption of the basal cell layer in these lesions and suggested a possible association between menin inactivation and the deregulation of AR expression.

\section{The reduced expression of CDKN1B was evidenced in prostatic carcinomas}

CDKN1B, an inhibitor of cyclin-dependent kinases, is a transcriptional target of the menin protein $[11,12]$. The involvement of its downregulation in the tumorigenesis of prostate cells has also been well documented in different mouse models and in prostate cancer patients $[19,20]$. We therefore analysed the expression of CDKN1B using IHC in serial sections of prostate carcinomas from $\mathrm{Men} 1^{+/-}$mice. Strong, predominantly nuclear CDKN1B expression was detected in virtually all luminal and basal $\mathrm{MenI}^{+/+}$prostate cells (Figure 4A, D), consistent with previous reports [21,22]. CDKN1B nuclear expression was clearly reduced in an in situ carcinoma (Figure 4B, E) and almost absent in an adenocarcinoma (Figure 4C, F) from $\mathrm{Men1}^{+/-}$mice. Furthermore, double IF staining with menin and CDKN1B antibodies showed that the reduced expression of CDKN1B in prostate carcinomas correlated well with the loss of menin expression (Figure $4 \mathrm{~K}-\mathrm{N}$ ), indicating that CDKN1B expression is indeed down-regulated in menin-negative prostatic cells.

\section{Discussion}

In the current study, analysis of a cohort of aged male $M e n 1^{+/-}$mice showed a significant reduction in the number of mutant mice with normal prostate glands due to the occurrence of prostate lesions in these mice. Interestingly, six mutant mice developed prostate cancer, which was not observed in the age-matched wildtype littermates. The prostate lesions found in heterozygous Men1 mutant mice were characterised by a slow cancer development process, which ranged from in situ carcinoma to invasive adenocarcinoma. This cancer development pattern in aged male heterozygous Men1 mice is similar to other non SV40-TAg GEM prostate cancer models, likely reflecting the relative late and slow features of prostate cancer development in men. Although one prostate cancer case was previously documented in an independent heterozygous Men1 mutant mouse cohort [7], to our knowledge, the present study is the first systematic evaluation and characterisation of prostate cancer related to the inactivation of the Men 1 gene.

Importantly, the menin protein was undetectable in cancerous cells, and partial $\mathrm{LOH}$ was found in three of five pre-and/or cancerous lesions from $M e n 1^{+/-}$mice. Menin loss in these mutant mice may indicate a close relationship between Men1 inactivation and the development of prostate cancer, suggesting that the Men1 gene may possess oncosuppressive activity and be involved in the control of cell proliferation in prostate epithelial cells. However, we noticed that the occurrence of prostate cancer in these mice can be seen only in aged mice with a low frequency, implying that Men1 inactivation may confer a relatively minor predisposition to prostate cancer development compared with the endocrine tissues affected in MEN1 pathology and that other factors may be involved in the development of this pathology. Interestingly, these results are similar to the findings with mice carrying either one mutated Pten or the $N k \times 3.1$ allele. Male heterozygous Pten mice develop mPIN at ages older than 9 months [19], whereas $N x k 3.1$ mutant mice show only hyperplastic or dysplastic prostatic epithelium [23]. However, the double mutant Pten ${ }^{+/-}: N \times k 3.1^{+/-}$mice display high grade PIN/early carcinoma lesions at a high frequency [24,25]. Both genes have been found either mutated or down-regulated in human prostate cancer $[19,26]$. The results of the present study suggest that the Men1 gene could be among the rare known tumour suppressors whose disruption leads to the development of prostate cancer in mice, albeit at low incidence and with a slow progression rate.

Intriguingly, a recent study reported that gain at the MEN1 locus was detected in a substantial proportion of human metastatic prostate cancers, and a trend toward increased menin expression in human prostate cancers and metastatic tissues was suggested by a meta-analysis of $M E N 1$ expression data in prostate cancer [27]. Similarly, Imachi et al. reported that menin expression in breast cancers could be used as a prognostic factor of worse outcome [28]. Knowing the multifaceted role played by the MEN1 gene, menin may play an oncogenic role under certain circumstances in these tissues, particularly in recurring and aggressive cancers, in similarity to the well-known dual role played by the TGF- $\beta$ pathway, whose several effectors are the protein partners of menin, in the process of tumourigenesis. However, further clinical studies are needed to validate these observations, as mentioned by the authors.

Our results suggest that the study of the potential link between menin and AR expression or activity in prostatic cells would be of great interest, as the latter is deregulated in the prostate cancers found in Men1 mutant mice. Generally considered a co-regulator of 


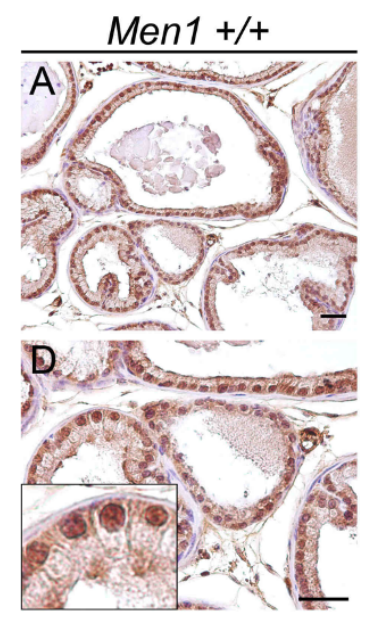

Menin/DAPI
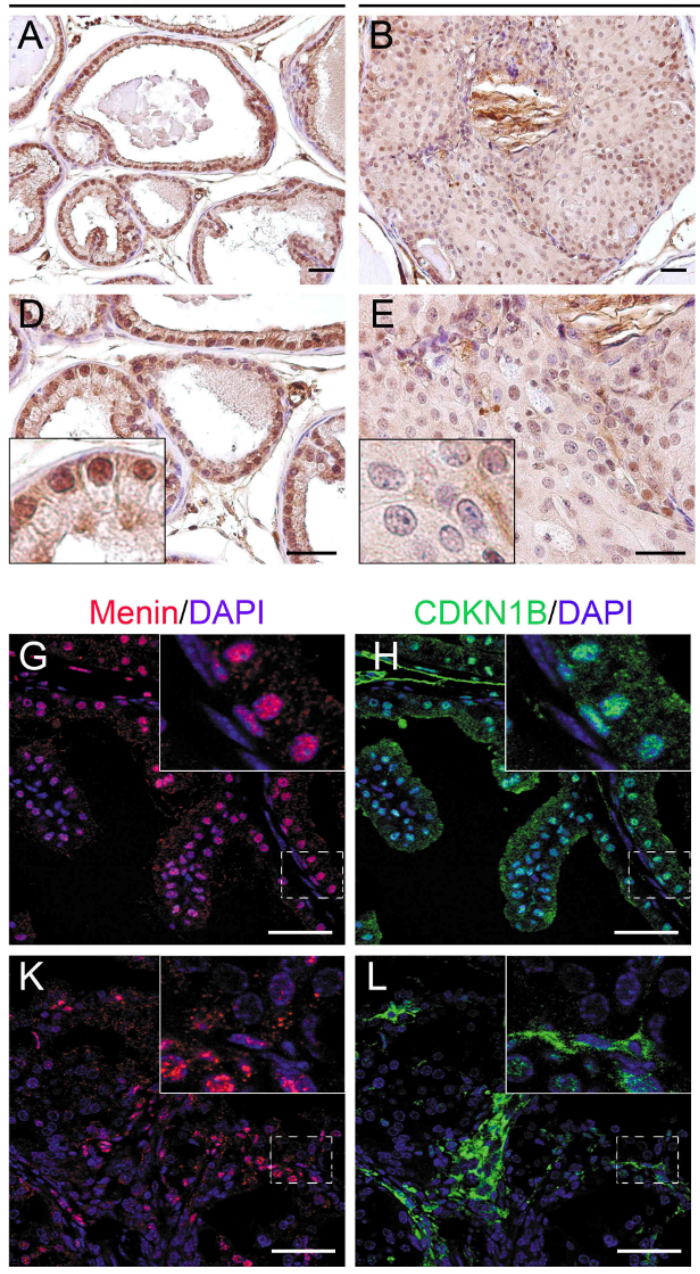

CDKN1B/DAPI

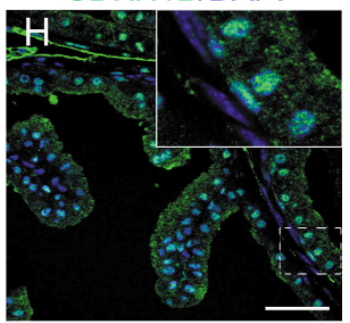

Men1+/-

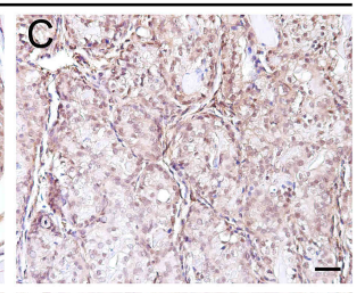

Menin/CDKN1B

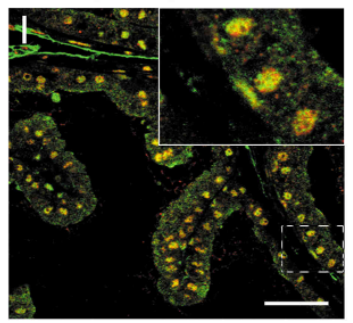

Menin/CDKN1B/DAPI

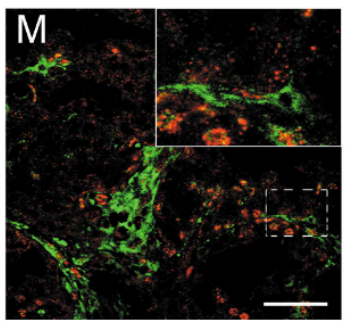

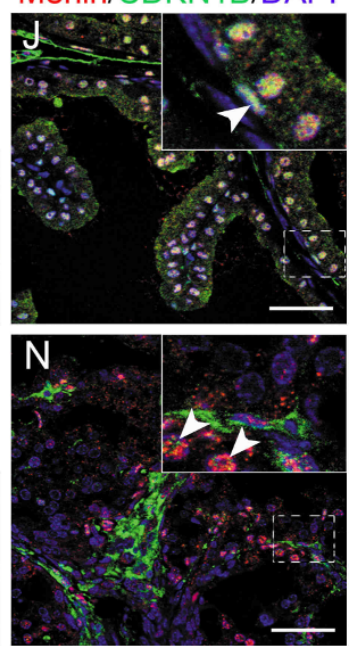

Figure 4 Reduced CDKN1B expression in prostate cancers from $M e n 1^{+/-}$mice. (A-F) $I H C$ was performed on paraffin-embedded sections of prostate tissues from Men1 $1^{+/+}(A, D, n=4)$ and $\operatorname{Men}^{+/-}(B, E$ and $C, F, n=4)$ mice using an antibody against CDKN1B. Note that in the normal prostate from aged $\mathrm{Men}^{+/+}$mice (26-month-old), CDKN1B is expressed in all prostatic epithelial cells, but not in all stromal cells (A, D). CDKN1B expression is reduced in an in situ carcinoma ( $B, E, 26$-month-old mouse) and an adenocarcinoma ( $C, F, 23-$ month-old mouse) from Men $1^{+/-}$mice when compared with the wild-type prostate. Panels D-F are two-fold magnifications of the upper panels (A-C). Insets show an amplified view of a part of the prostate glands. (G-N) Menin (red) and CDKN1B (green) expressions examined by double IF staining in prostate glands from a 21month-old Men 1 wild-type mouse (G-J) and an adenocarcinoma from a 23 -month-old Men ${ }^{+/-}$mouse (K-N). DAPI stains cell nuclei. Note that menin and CDKN1B expressions are co-localised in normal prostate epithelium, whereas both disappear in the cancerous lesions. Arrowheads show that basal cells remain both menin and CDKN1B positive in cancerous lesions. Boxed areas are magnified in the insets. Scale bars, $50 \mu$ m.

transcription, menin interacts physically and functionally with several nuclear receptors, such as ER $\alpha$ [9] and PPAR $\gamma$ [10], playing the role of a transcriptional coactivator via its LXXLL motif. Although a physical interaction between menin and AR has not been reported yet, the existence of cross-talk between menin and the AR pathways is possible. Indeed, menin and AR share common partners like Smad3, a downstream effector of the TGF- $\beta$ signalling pathway, and $\beta$-catenin, an effector of WNT pathway [4,29], but also common target genes important for cell cycle control, such as CDKN1B and cyclins $D[4,11,12,30,31]$. The observation of deregulated
AR expression in the cancerous lesions found in Men1 mutant mice suggests that menin inactivation and subsequent AR deregulation in these cells may lead to the disturbance of the AR pathway, which could in turn promote the progression to cancer.

It is worth mentioning that the mutant mice enrolled in this study developed Leydig cell tumours with high frequency, which could suggest that the occurrence of these tumours plays a role in the tumorigenesis of prostate cells. However, the data from previously published mouse models of Leydig cell tumours did not offer any evidence supporting this hypothesis, as none reported 
prostate lesions [32-36]. Furthermore, AR signalling seems to play a growth suppressing function in the initial stage of tumour development [30]. Nevertheless, it will be interesting in the future to investigate the possible interplay between the development of Leydig cell tumours and the occurrence of prostate cancer.

Prior studies have proposed that the growth inhibition function of AR signalling in normal prostatic luminal cells is mediated by its induction of CDKN1B expression [30]. This indeed correlates with the downregulation of CDKN1B observed in prostate carcinomas developed in our Men1 mutant mice. CDKN1B, which is closely related to the tumorigenesis of prostate cancers as described above, is among the transcriptional targets of menin. The mouse models with $C D K N 1 B$ disruption in combination with other genetic factors, such as Pten and $N k \times 3.1$, have been shown to develop a range of prostate cancers, although CDKN1B inactivation alone displays no obvious neoplastic prostate lesions $[19,25]$. The downregulation of CDKN1B found in prostate lesions in Men1 mutant mice suggests the in vivo importance of CDKN1B inactivation in the tumorigenesis related to Men1 inactivation, similar to observations in other mouse Men1 tumour models [12,37-39]. Furthermore, it would be interesting to clarify the possible relation between menin and other factors involved in CDKN1B regulation in the prostate, such as Pten and $\mathrm{Nkx} 3.1$, in the future.

\section{Conclusion}

The presented data suggest the possible involvement of Men1 inactivation in the tumorigenesis of prostatic cells in mice. Recent extensive genetic studies highlighted the difficulties in identifying genes involved in the tumorigenesis of prostate cells [40], indicating that prostate cancer could be a genetically complex disease with multiple predisposing factors affecting initiation, progression, and outcome of the disease. It would thus be interesting to investigate the eventual oncosuppressive role of the Men1 gene in prostatic cells in humans in the future. The current study also suggests that both altered AR and CDKN1B expression may be among the factors participating in or facilitating the tumorigenesis of prostatic cells due to Men1 inactivation.

\footnotetext{
Acknowledgements

This study was supported by the Association pour la Recherche contre le Cancer, France, the Ligue contre le Cancer du Rhône and de la Loire, and MIRA-2008 Région Rhône-Alpes. During this study, CS was the recipient of fellowships from French government and of Association pour la Recherche contre le Cancer. SF was the recipient of fellowships from Ligue contre le Cancer de la Loire, France. We thank Dominique Galendo and Marie-Pierre Cros for the maintenance of the mouse colonies, the colleagues at the "Groupe d'Etude Recherche, CNRS N²906, France" for scientific discussion, as well as George Hinkal and Neela Guha for the correction of the manuscript.
}

\section{Author details}

'CNRS UMR5201, Laboratoire de Génétique Moléculaire, Signalisation et Cancer, Centre Léon Bérard, Lyon F-69008, France. ${ }^{2}$ International Agency for Research on Cancer, Lyon F-69008, France. ${ }^{3}$ Institute of Basic Medical Sciences, Academy of Medical Sciences, Beijing Union Medical College, Beijing-100005, China. ${ }^{4}$ Département de Pathologie, Centre Léon Bérard, Lyon F-69008, France. ${ }^{5}$ Leibniz Institute for Age Research - Fritz Lipmann Institute e.V., 07745 Jena, Germany. ${ }^{6}$ Département de Pathologie, INSERM U590, Centre Léon Bérard, Hôpital Edouard Herriot, HCL, Lyon F-69008, France. ${ }^{7}$ The E-Institute of Shanghai, Sino-French Life Science and Genomic Research Center, Jiaotong University, Shanghai, China.

\section{Authors' contributions}

CS conducted most of the experiments, analysed data and prepared figures; SF maintained the mouse colony and collected tissues; CC performed experiments, in particular histological analyses; $J$ provided experimental advice and assistance; WMT, BF and LF performed the histopathological analyses; ZQW supervised the experiments and helped preparing the manuscript; and CXZ and LF conceived the study, supervised the overall project, analysed data and wrote the manuscript. All authors read and approved the final manuscript.

\section{Competing interests}

The authors declare that they have no competing interests.

Received: 11 December 2009 Accepted: 27 July 2010

Published: 27 July 2010

\section{References}

1. Thakker RV: Multiple endocrine neoplasia-syndromes of the twentieth century. J Clin Endocrinol Metab 1998, 83(8):2617-2620.

2. Boni $R$, Vortmeyer AO, Pack S, Park WS, Burg G, Hofbauer G, Darling T, Liotta L, Zhuang Z: Somatic mutations of the MEN1 tumor suppressor gene detected in sporadic angiofibromas. J Invest Dermatol 1998, 111(3):539-540.

3. Hofmann M, Schilling T, Heilmann P, Haisken O, Wuster C, Brandi ML, Ziegler R, Nawroth PP: [Multiple endocrine neoplasia associated with multiple lipomas]. Med Klin (Munich) 1998, 93(9):546-549.

4. Yang $Y$, Hua $X$ : In search of tumor suppressing functions of menin. Mol Cell Endocrinol 2007, 265-266:34-41.

5. Bertolino P, Radovanovic I, Casse H, Aguzzi A, Wang ZQ, Zhang CX: Genetic ablation of the tumor suppressor menin causes lethality at midgestation with defects in multiple organs. Mech Dev 2003, 120(5):549-560.

6. Bertolino P, Tong WM, Galendo D, Wang ZQ, Zhang CX: Heterozygous Men1 mutant mice develop a range of endocrine tumors mimicking multiple endocrine neoplasia type 1. Mol Endocrinol 2003, 17(9):1880-1892.

7. Crabtree JS, Scacheri PC, Ward JM, Garrett-Beal L, Emmert-Buck MR, Edgemon KA, Lorang D, Libutti SK, Chandrasekharappa SC, Marx SJ, Spiegel AM, Collins FS: A mouse model of multiple endocrine neoplasia, type 1, develops multiple endocrine tumors. Proc Natl Acad Sci USA 2001, 98(3):1118-1123

8. Loffler KA, Biondi CA, Gartside M, Waring P, Stark M, Serewko-Auret MM, Muller HK, Hayward NK, Kay GF: Broad tumor spectrum in a mouse model of multiple endocrine neoplasia type 1. Int J Cancer 2007, 120(2):259-267.

9. Dreijerink KM, Mulder KW, Winkler GS, Hoppener JW, Lips CJ, Timmers HTM: Menin links estrogen receptor activation to histone H3K4 trimethylation. Cancer Res 2006, 66(9):4929-4935.

10. Dreijerink KMA, Varier RA, van Beekum O, Jeninga EH, Hoppener JWM, Lips CJM, Kummer JA, Kalkhoven E, Timmers HTM: The Multiple Endocrine Neoplasia type 1 (MEN1) tumor suppressor regulates PPAR\{gamma\}dependent adipocyte differentiation. Mol Cell Biol 2009, 29(18):5060-5069, MCB.01001-01008.

11. Milne TA, Hughes CM, Lloyd R, Yang Z, Rozenblatt-Rosen O, Dou Y, Schnepp RW, Krankel C, Livolsi VA, Gibbs D, Hua X, Roeder RG, Meyerson M, Hess JL: Menin and MLL cooperatively regulate expression of cyclindependent kinase inhibitors. Proc Natl Acad Sci USA 2005, 102(3):749-754

12. Karnik SK, Hughes CM, Gu X, Rozenblatt-Rosen O, McLean GW, Xiong Y, Meyerson M, Kim SK: Menin regulates pancreatic islet growth by promoting histone methylation and expression of genes encoding p27Kip1 and p18INK4c. Proc Natl Acad Sci USA 2005, 102(41):14659-14664. 
13. Shappell SB, Thomas GV, Roberts RL, Herbert R, Ittmann MM, Rubin MA, Humphrey PA, Sundberg JP, Rozengurt N, Barrios R, Ward JM, Cardiff RD: Prostate pathology of genetically engineered mice: definitions and classification. The consensus report from the Bar Harbor meeting of the Mouse Models of Human Cancer Consortium Prostate Pathology Committee. Cancer Res 2004, 64(6):2270-2305.

14. Liu Y, Mo JQ, Hu Q, Boivin G, Levin L, Lu S, Yang D, Dong Z: Targeted Overexpression of Vav3 Oncogene in Prostatic Epithelium Induces Nonbacterial Prostatitis and Prostate Cancer. Cancer Res 2008, 68(15):6396-6406.

15. Weinstein $M H$, Signoretti S, Loda M: Diagnostic Utility of Immunohistochemical Staining for p63, a Sensitive Marker of Prostatic Basal Cells. Mod Pathol 2002, 15(12):1302-1308.

16. Tsurusaki T, Aoki D, Kanetake H, Inoue S, Muramatsu M, Hishikawa Y, Koji T: Zone-dependent expression of estrogen receptors alpha and beta in human benign prostatic hyperplasia. J Clin Endocrinol Metab 2003, 88(3):1333-1340.

17. Svensson J, Kindblom J, Shao R, Moverare-Skrtic S, Lagerquist MK, Andersson N, Sjogren K, Venken K, Vanderschueren D, Jansson JO, Isaksson O, Ohlsson C: Liver-derived IGF1 enhances the androgenic response in prostate. J Endocrinol 2008, 199(3):489-497.

18. Ishii K, Imanaka-Yoshida K, Yoshida T, Sugimura Y: Role of stromal tenascin- $C$ in mouse prostatic development and epithelial cell differentiation. Developmental Biology 2008, 324(2):310-319.

19. Di Cristofano A, De Acetis M, Koff A, Cordon-Cardo C, P Pandolfi P: Pten and p27KIP1 cooperate in prostate cancer tumor suppression in the mouse. Nat Genet 2001, 27(2):222-224.

20. Macri E, Loda M: Role of p27 in prostate carcinogenesis. Cancer Metastasis Rev 1998, 17(4):337-344.

21. Trotman LC, Niki M, Dotan ZA, Koutcher JA, Di Cristofano A, Xiao A, Khoo AS, Roy-Burman P, Greenberg NM, Van Dyke T, Cordon-Cardo C, Pandolfi PP: Pten dose dictates cancer progression in the prostate. PLoS Biol 2003, 1(3):E59.

22. Zhong C, Saribekyan G, Liao C-P, Cohen MB, Roy-Burman P: Cooperation between FGF8b Overexpression and PTEN Deficiency in Prostate Tumorigenesis. Cancer Res 2006, 66(4):2188-2194.

23. Bhatia-Gaur R, Donjacour AA, Sciavolino PJ, Kim M, Desai N, Young P, Norton CR, Gridley T, Cardiff RD, Cunha GR, Abate-Shen C, Shen MM: Roles for Nkx3.1 in prostate development and cancer. Genes Dev 1999, 13(8):966-977.

24. Kim MJ, Cardiff RD, Desai N, Banach-Petrosky WA, Parsons R, Shen MM, Abate-Shen C: Cooperativity of Nkx3.1 and Pten loss of function in a mouse model of prostate carcinogenesis. Proceedings of the National Academy of Sciences of the United States of America 2002, 99(5):2884-2889.

25. Gao H, Ouyang $X$, Banach-Petrosky W, Borowsky AD, Lin Y, Kim M, Lee H, Shih WJ, Cardiff RD, Shen MM, Abate-Shen C: A critical role for p27kip1 gene dosage in a mouse model of prostate carcinogenesis. Proc Natl Acad Sci USA 2004, 101(49):17204-17209.

26. Bowen C, Bubendorf L, Voeller HJ, Slack R, Willi N, Sauter G, Gasser TC, Koivisto P, Lack EE, Kononen J, Kallioniemi OP, Gelmann EP: Loss of NKX3.1 expression in human prostate cancers correlates with tumor progression. Cancer Research 2000, 60:6111-6115.

27. Paris $P L$, Sridharan $S$, Hittelman AB, Kobayashi $Y$, Perner $S$, Huang G, Simko J, Carroll P, Rubin MA, Collins C: An oncogenic role for the multiple endocrine neoplasia type 1 gene in prostate cancer. Prostate Cancer Prostatic Dis 2009, 12(2):184-91.

28. Imachi H, Murao K, Dobashi H, Bhuyan MM, Cao X, Kontani K, Niki S, Murazawa C, Nakajima H, Kohno N, Yamashita H, Iwase H, Hayashi SI, Ishida T, Yamauchi A: Menin, a product of the MENI gene, binds to estrogen receptor to enhance its activity in breast cancer cells: possibility of a novel predictive factor for tamoxifen resistance. Breast Cancer Res Treat 2009, 122(2):395-407.

29. Kang HY, Huang KE, Chang SY, Ma WL, Lin WJ, Chang C: Differential Modulation of Androgen Receptor-mediated Transactivation by Smad3 and Tumor Suppressor Smad4. Journal of Biological Chemistry 2002, 277:43749-43756.

30. Litvinov IV, De Marzo AM, Isaacs JT: Is the Achilles' Heel for Prostate Cancer Therapy a Gain of Function in Androgen Receptor Signaling? J Clin Endocrinol Metab 2003, 88(7):2972-2982.

31. $\mathrm{Xu} \mathrm{Y,} \mathrm{Chen} \mathrm{SY,} \mathrm{Ross} \mathrm{KN,} \mathrm{Balk} \mathrm{SP:} \mathrm{Androgens} \mathrm{induce} \mathrm{prostate} \mathrm{cancer} \mathrm{cell}$ proliferation through mammalian target of rapamycin activation and post-transcriptional increases in cyclin D proteins. Cancer Research 2006, 66(15):7783-92.

32. Matzuk MM, Finegold MJ, Su J-GJ, Hsueh AJW, Bradley A: [alpha]-Inhibin is a tumour-suppressor gene with gonadal specificity in mice. Nature 1992, 360(6402):313-319.

33. Behringer RR, Finegold MJ, Cate RL: Müllerian-inhibiting substance function during mammalian sexual development. Cell 1994, 79(3):415-425.

34. Matzuk MM, Finegold MJ, Mishina Y, Bradley A, Behringer RR: Synergistic effects of inhibins and mullerian-inhibiting substance on testicular tumorigenesis. Mol Endocrinol 1995, 9(10):1337-1345.

35. Mishina Y, Rey R, Finegold MJ, Matzuk MM, Josso N, Cate RL, Behringer RR: Genetic analysis of the Mullerian-inhibiting substance signal transduction pathway in mammalian sexual differentiation. Genes \& Development 1996, 10(20):2577-2587.

36. Franklin DS, Godfrey VL, O'Brien DA, Deng C, Xiong Y: Functional Collaboration between Different Cyclin-Dependent Kinase Inhibitors Suppresses Tumor Growth with Distinct Tissue Specificity. Mol Cell Biol 2000, 20(16):6147-6158.

37. Hussein N, Lu J, Casse H, Fontaniere S, Morera AM, Guittot SM, Calender A, Di Clemente N, Zhang CX: Deregulation of anti-Mullerian hormone/BMP and transforming growth factor-beta pathways in Leydig cell lesions developed in male heterozygous multiple endocrine neoplasia type 1 mutant mice. Endocr Relat Cancer 2008, 15(1):217-227.

38. Hussein N, Casse H, Fontaniere S, Morera AM, Asensio MJ, Bakeli S, Lu JL, Coste I, Di Clemente N, Bertolino P, Zhang CX: Reconstituted expression of menin in Men1-deficient mouse Leydig tumour cells induces cell cycle arrest and apoptosis. Eur J Cancer 2007, 43(2):402-414.

39. Fontaniere S, Casse H, Bertolino P, Zhang CX: Analysis of p27(Kip1) expression in insulinomas developed in pancreatic beta-cell specific Men1 mutant mice. Fam Cancer 2006, 5(1):49-54.

40. Thomas G, Jacobs KB, Yeager M, Kraft P, Wacholder S, Orr N, Yu K, Chatterjee N, Welch R, Hutchinson A, Crenshaw A, Cancel-Tassin G, Staats BJ, Wang Z, Gonzalez-Bosquet J, Fang J, Deng X, Berndt SI, Calle EE, Feigelson HS, Thun MJ, Rodriguez C, Albanes D, Virtamo J, Weinstein S, Schumacher FR, Giovannucci E, Willett WC, Cussenot O, Valeri A, et al: Multiple loci identified in a genome-wide association study of prostate cancer. Nat Genet 2008, 40(3):310-315.

\section{Pre-publication history}

The pre-publication history for this paper can be accessed here: http://www.biomedcentral.com/1471-2407/10/395/prepub

doi:10.1186/1471-2407-10-395

Cite this article as: Seigne et al:: Characterisation of prostate cancer lesions in heterozygous Men1 mutant mice. BMC Cancer 2010 10:395.

\section{Submit your next manuscript to BioMed Central and take full advantage of:}

- Convenient online submission

- Thorough peer review

- No space constraints or color figure charges

- Immediate publication on acceptance

- Inclusion in PubMed, CAS, Scopus and Google Scholar

- Research which is freely available for redistribution

Submit your manuscript at www.biomedcentral.com/submit
C Biomed Central 